\title{
Копинг-стратегии одаренных подростков с разным уровнем субъективного контроля
}

\author{
Елена В. Зинченко*, Анна А. Алтынова \\ Южный федеральный университет, г. Ростов-на-Аону, Россия \\ *E-mail: evzinchenko@sfedu.ru
}

\begin{abstract}
Аннотация
В статье рассматривается проблема копинга у одаренных цетей. Авторы обращают внимание на популярность тенденции оказания помощи Аля развития способностей оАаренных поАростков, в виАе мощной внешней поААержки со стороны государства и созАания благоприятных условий Аля их обучения, и опреАеляют актуальность проблемы психологического сопровожАения одаренных. Важную роль в Аостижении успеха обучающимися играет их психологическая устойчивость переА стрессовыми ситуациями, с которыми они постоянно сталкиваются. В статье Аается теоретический анализ митературы по Аанной проблеме.

ИсслеАование копинг-стратегий одаренных подростков и уровня их субъективного контроля осуществля^ось с помощью тестирования (опросник «СОРЕ» в аАаптации Е. И. Рассказовой, Т. О. Гордеевой, Е. Н. Осина; методика «УСК» Е. Ф. Бажина, Е. А. Голынкиной, А. М. Эткинда), метода описательной статистики и математического метода обработки Аанных.

Основными результатами исслеАования явились выводы о том, что оАаренные Аети предпочитают продуктивные копинг-стратегии, они склонны п^анировать решение проблемы и активно справляться с трудностями в стрессовой ситуации. Авторами Аается описание различий в использовании копинг-стратегий одаренными поАростками с экстернальным и интернальным локусами контроля. Исследование гендерных особенностей в применении копинг-стратегий показало значимые различия межАу одаренными Аевушками и юношами в четырех способах совлаАания: мысленный ухоА от проблемы, концентрация на эмоциях, использование эмоциональной социальной подАержки и использование «успокоительных». Отмечается, что одаренные Аевушки имеют более высокий уровень субъективного контроля наА значимыми ситуациями, чем юноши. В заключение сАелан вывол о необходимости разработки психологической коррекционной программы Аля фоормирования продуктивных копинг-стратегий у одаренных подростков с экстернальным типом ^окуса контроля.
\end{abstract}

\section{КАючевые слова}

одаренность, копинг-стратегии, совладающее повеАение, подростки, субъективный контроль, Аокус контроля, экстернальность, интернальность, психологическое сопровожАение, стресс 
ОБЩАЯ ПСИХОЛОГИЯ, ПСИХОЛОГИЯ ЛИЧНОСТИ

Аля цитирования: Зинченко Е. В., Алтынова А. А. Копинг-стратегии одаренных поАростков с разным уровнем субъективного контроля // Северо-Кавказский психо^огический вестник. 2020. № 18/2. С. 15-27. doi: 10.21702/ncpb.2020.2.2

\title{
Coping strategies of gifted teenagers with different levels of subjective control
}

\author{
Elena V. Zinchenko*, Anna A. Altynova \\ Southern Federal University, Rostov-on-Don, Russia \\ *Corresponding author. E-mail: evzinchenko@sfedu.ru
}

\begin{abstract}
The article deals with the problem of coping in gifted children. The authors draw attention to the popularity of the tendency to help gifted teenagers to develop their abilities in the form of strong external support from the state and creating favourable conditions for their learning and determine the relevance of the problem of psychological support for the gifted. An important role in the success of students is played by their psychological resilience to the stressful situations they constantly face. The article gives a theoretical analysis of the literature on this problem.

The research of coping-strategies of gifted teenagers and their level of subjective control was carried out by means of testing ("COPE" questionnaire adapted by E. I. Rasskazova, T. O. Gordeeva, E. N. Osin; modification of Rotter's Internal-External Locus of Control Scale by E. F. Bazhin, E. A. Golynkina, L. M. Etkind), method of descriptive statistics and mathematical method of data processing.

The main results of the study were the conclusions that gifted children prefer productive coping strategies; they tend to plan problem solving and actively cope with difficulties in a stressful situation. The authors describe the differences in the use of coping strategies by gifted adolescents with external and internal locus of control. The study of gender peculiarities in the use of coping strategies showed significant differences between gifted girls and boys in 4 ways of coping: mental withdrawal from the problem, concentration on emotions, use of emotional social support and use of "sedatives". It was noted that gifted girls have a higher level of subjective control over significant situations. At the end of the article it was concluded that it is necessary to develop a psychological correction program for the formation of productive coping strategies in gifted adolescents with an external type of locus of control.
\end{abstract}

\section{Keywords}

giftedness, coping strategies, coping behavior, adolescents, subjective control, locus of control, externality, internality, psychological support, stress 
For citation: Zinchenko E. V., Altynova A. A. Coping strategies of gifted teenagers with different levels of subjective control. Severo-Kavkazskii psikhologicheskii vestnik = North-Caucasian Psychological Bulletin, 2020, no. 18/2, pp. 15-27. doi: 10.21702/ ncpb.2020.2.2 (in Russ.).

\section{ВВЕДЕНИЕ}

Феномен одаренности активно исследуется учеными в течение многих лет. Однако в последнее время можно наблюдать смещение акцентов внимания психологов и педагогов в данной области исследований с самого понятия одаренности и его характеристик на изучение внешних и внутренних условий, особенностей развития детской и подростковой одаренности. Все более актуальными становятся научные работы, посвященные разработке средств и методов психологической поддержки одаренных школьников. Для современных детей создаются благоприятные внешние условия в виде обучения в специализированных учебных заведениях, созданных по указу Президента РФ, научных центрах, участия в грантах и предоставляются другие возможности для раскрытия творческого потенциала, развития способностей. При этом вопрос индивидуального и группового психолого-педагогического сопровождения одаренных детей не решен до конца. Исследователи указывают, что лишь 2-3 \% одаренных подростков реализуют в дальнейшем свой потенциал в профессиональной сфере [1]. Следовательно, необходимо формировать систему психологического сопровождения одаренных детей с учетом их возрастных особенностей и специфики области деятельности, в которой они достигли значительных успехов. Особо значимым и актуальным становится исследование копинг-стратегий одаренных обучающихся в современных условиях жизнедеятельности, отличающихся высокой изменчивостью. Возникновение жизненных трудностей актуализирует копинг-поведение, реализуемое личностью посредством ряда копинг-стратегий. Важно понимать полную картину возможных способов реагирования старшеклассников в трудной стрессовой ситуации и способствовать расширению индивидуального репертуара копинг-стратегий, ориентируя на гибкость их применения с учетом конкретной ситуации [2].

\section{Теоретическое обоснование}

Согласно постановлению Правительства РФ от 17 ноября 2015 г. № 1239 были утверждены Правила выявления, сопровождения и мониторинга дальнейшего развития детей, проявивших выдающиеся способности. В редакции Постановления Правительства РФ от 27.05.2020 № 760 описывается, что выявление одаренных детей осуществляется на основе наличия личных достижений в виде запатентованных результатов интеллектуальной деятельности или публикации в научном международном издании, либо посредством 
проведения олимпиад и других интеллектуальных, спортивных или творческих конкурсов, а также различных мероприятий, направленных на развитие способностей и интереса к научной, творческой, спортивной деятельности, и на пропаганду научных знаний и достижений в своей сфере деятельности. Следовательно, согласно сказанному выше, школьники, имеющие документально подтвержденные высокие достижения в той или иной области, могут рассматриваться как одаренные.

В психологии существует большое количество определений одаренности. Различают общую и специальную одаренность. Под общей одаренностью понимается интеллектуальный, творческий или спортивный потенциал, заложенный природой и проявляющийся в любом возрастном периоде, при этом способности имеются во многих сферах деятельности. Специальная одаренность обозначает проявление таланта в одной определенной отрасли [3]. Одаренный ребенок отличается высокой познавательной активностью и развитием интеллекта выше сверстников, имеет большой словарный запас, хорошую эрудицию и творческие способности. Н. С. Лейтес отмечает, что большинство одаренных детей обладают развитым чувством юмора [4]. Одновременно одаренным обучающимся присуща эмоциональная уязвимость и сверхчувствительность, обусловленные особенностями их интеллектуального развития. Они чаще, чем сверстники, могут подвергаться одиночеству и изоляции, находиться в тревожном состоянии, остро переживая неудачи [5]. Собственно, поэтому психологами так часто описывается необходимость в комплексном психологическом сопровождении одаренных детей и применении к ним индивидуального подхода в обучении, профессиональной диагностике [6]. Реализации такого подхода может способствовать изучение психофизиологических основ детской одаренности. Ученые активно исследуют мозговые механизмы творческой деятельности одаренных людей, изучают изменения биоэлектрической активности коры головного мозга при решении интеллектуальных задач [7]. В наши дни реализация интеллектуального и творческого потенциала одаренных детей является актуальной социальной и национальной задачей.

Президиум Государственного Совета Российской Федерации с 2010 г. ввел в систему образовательных учреждений требование по развитию одаренности учащихся на основе непрерывной образовательной траектории. В психологии популярными программами работы с одаренными являются: «Методика полного усвоения» Дж. Кэррола и Б. Блума, «Три вида обогащения учебной программы» Дж. Рензулли, «Таксономия целей обучения» Б. Блума и др. [8]. Анализируя литературу по данной проблеме, можно определить, что сопровождение одаренных детей может осуществляться в трех направлениях. Это развитие собственно интеллектуальных, творческих или спортивных способностей ребенка, формирование адекватного самовосприятия, эмоционально-волевой 
сферы и поведенческих реакций, а также помощь в адаптации обучающегося к социальному окружению и приобретении конструктивных форм общения. Американский психолог Б. Блум предложил модель специальных воспитательных и образовательных средств для развития таланта одаренных. Он провел множество интервью с известными личностями в различных сферах деятельности и доказал влияние поддержки семьи и ближайшего окружения на успешность одаренного ребенка [9].

Многими учеными отмечалось, что существуют два фактора, способствующих реализации потенциала одаренного ребенка: внутренние характеристики, такие как мотивация достижения, стратегии обучения, эмоции, копинг-стратегии, и внешние - социум, культура, семья, ближайшее окружение, критические жизненные события. При этом, согласно А. Циглеру и Х. Стоеджеру, на ранних этапах обучения внешние факторы больше влияют на успех развития способностей учащихся [10]. Таким образом, авторы утверждают, что оказывать психологическое сопровождение одаренным обучающимся крайне необходимо.

Обучение одаренных детей отличается определенной спецификой. Одаренные подростки подвержены регулярным стрессовым нагрузкам, связанным с насыщенной событиями жизнью, напряженной интеллектуальной деятельностью (обусловленной постоянным участием в олимпиадах, конференциях, конкурсах, проектах и т. д.). Часто стрессовые нагрузки сочетаются с ощущением своей инаковости, завышенными требованиями к себе, трудностями общения со сверстниками и пр. Поведение подростков в стрессовой ситуации определяется системой различных внешних и внутренних факторов и сопровождается применением определенных копинг-стратегий [11]. Австралийские ученые К. Эддлс-Хирш, У. Виалл, Дж. МакКормик и К. Роджерс исследовали стратегии совладания одаренных школьников в различных учебных условиях. Удалось определить, что школы, осуществляющие поддержку для удовлетворения социальных и эмоциональных потребностей одаренных обучающихся, обеспечили такие условия, в которых неадаптивное совладание не развивалось [12]. Для проведения проектных смен и наиболее результативного осуществления процесса обучения и исследовательской подготовки одаренных школьников объединяют в малые группы. Однако, как отмечают исследователи, в группах, работающих совместно над достижением единых целей, могут возникать конфликты различного уровня (межличностные, конфликты микрогрупп, групповые) и типа (конфликт работы и конфликт субъектов), влияющие на эффективность группы [13]. Наиболее часто конфликты возникают при реализации копинг-стратегии конфронтации или же других непродуктивных стратегий.

На сегодняшний день проблемой копинг-стратегий занимается множество ученых, изучая различные аспекты их детерминации: гендер, возраст, 
личностные особенности, принадлежность к расе и пр. Однако исследованию адаптивных и неадаптивных копинг-стратегий молодых людей уделяется меньше внимания [14]. С. А. Хазова отмечает качественное отличие совладающего поведения одаренных старшеклассников и их сверстников. Одаренные обучающиеся реже используют стратегию социальной поддержки, им свойственно замыкаться в себе и не делиться своими переживаниями [15]. В своем исследовании И. М. Никольская и Р. М. Грановская описали стратегию когнитивного отвлечения в качестве приоритетной для одаренных школьников, что связано с их способностью к саморегуляции [16]. В психологических научных исследованиях в роли предиктора эффективного совладающего поведения можно встретить такую личностную характеристику, как локус контроля. С. А. Яковлева выделила локус контроля в качестве одного из факторов детерминации совладающего поведения подростков. Так, ей удалось выявить, что школьники с интернальным локусом контроля воспринимают стрессовые события как вызов, чаще используют продуктивные копинг-стратегии; подростки же с экстернальным локусом контроля склонны покорно переносить стресс, не пытаясь изменить ситуацию, зачастую они применяют непродуктивные стратегии совладания [17].

Цель нашего исследования: изучить копинг-стратегии одаренных подростков, адаптирующихся в новом образовательном учреждении. Обучающиеся СУНЦ ЮФО - это школьники, имеющие достижения в области математическо-технических, гуманитарных и информационных наук. Отбор школьников для обучения в СУНЦ осуществлялся конкурсной комиссией ЮФУ по нескольким критериям: на основе результатов портфолио, подтверждающего их значимые научные достижения в определенной области (победы или призовые места в олимпиадах и конкурсах разного уровня), предметного и психологического тестирования. К зачислению были рекомендованы школьники, набравшие по итогам конкурса наиболее высокие результаты по сравнению со сверстниками, что позволяет, учитывая обозначенные выше подходы к понятию одаренности, отнести их к числу одаренных.

Каждый обучающийся, переходящий в другое образовательное учреждение, сталкивается с изменением условий и режима обучения. Специфика обучения в СУНЦ ЮФО заключается в: усилении акцента на исследовательской деятельности и олимпиадной подготовке; необходимости работы обучающихся в проектных группах; появлении педагогов-наставников, курирующих исследовательскую деятельность и др. Часто при этом подросток вынужден переехать в другой город и начать самостоятельную жизнь вдали от родителей. Перечисленные обстоятельства вызывают у обучающихся стресс, возникающий как пусковой механизм адаптационного процесса. Для успешного совладания с новой жизненной ситуацией одаренные школьники используют различные 
стратегии совладающего поведения, которые помогают им адаптироваться к новым условиям обучения.

\section{МЕТОДЫ}

Для исследования копинг-стратегий одаренных подростков с разным уровнем субъективного контроля нами использовались опросник совладания со стрессом «СОРЕ» в адаптации Е. И. Рассказовой, Т. О. Гордеевой, Е. Н. Осина, а также методика «УСК», разработанная Е. Ф. Бажиным, Е. А. Голынкиной, Л. М. Эткиндом. Математическая обработка данных осуществлялась с помощью непараметрического U-критерия Манна - Уитни. В исследовании приняли участие 40 одаренных подростков в возрасте 16-17 лет, обучающихся в СУНЦ ЮФО в течение 2-3 месяцев, из них 22 девочки и 18 мальчиков.

\section{РЕЗУЛЬТАТЫ И ИХ ОБСУЖДЕНИЕ}

Эмпирически установлено, что наиболее предпочитаемой стратегией одаренных подростков является стратегия планирования (таблица 1). Это свидетельствует о том, что школьники в стрессовой ситуации склонны думать о возможностях преодоления актуальной проблемы. Приоритетной также является и стратегия активного совладания, что отражается в применении активных прямых действий, направленных на разрешение тяжелой жизненной ситуации. Еще одна тенденция просматривается в применении респондентами стратегий позитивного переформулирования и личностного роста, когда стрессовая ситуация переосмысляется в позитивном ключе, и юмора. Между инструментальной и эмоциональной социальной поддержкой одаренные школьники выбирают скорее инструментальную: они более сконцентрированы на деле, чем на переживаниях. При этом стратегия соперничества и подавления конкурирующей деятельности рассматривается ими как возможная для применения в определенных обстоятельствах.

Наименее используемыми стратегиями совладания являются стратегии обращения к религии и использования «успокоительных», поведенческого ухода. Интеллектуально одаренные дети больше склонны обращаться к себе, своим мыслям, чем прибегать к помощи веры, религии или применять медикаментозные средства для улучшения самочувствия в стрессовой ситуации. Тем самым делаем вывод о том, что одаренные подростки выбирают преимущественно продуктивные стратегии совладания со стрессом, предпочитают решать проблемы, а не уходить от их решения.

При решении задачи, касающейся установления гендерных предпочтений применения копинг-стратегий, нами были выявлены значимые различия в копинге между одаренными юношами и девушками. Так, девушки чаще юношей выбирают стратегии мысленного ухода от проблемы $\left(U_{\text {эмп }}=107,5\right.$ при $\left.\mathrm{p} \leq 0,05\right)$ 
ОБЩАЯ ПСИХОЛОГИЯ, ПСИХОЛОГИЯ ЛИЧНОСТИ

и концентрации на эмоциях $\left(U_{\text {эмп }}=126\right.$ при $\left.p \leq 0,05\right)$, хотя данная стратегия не является одной из наиболее предпочитаемых. А также они чаще, чем юноши, применяют стратегии использования эмоциональной социальной поддержки $\left(U_{\text {эмп }}=132\right.$ при $\left.p \leq 0,05\right)$ и использования «успокоительных» $\left(U_{\text {эмп }}=116,5\right.$ при $\mathrm{p} \leq 0,05)$. Эмоционально-ориентированные копинг-стратегии являются менее эффективными, чем проблемно-ориентированные. У девушек выражена потребность в эмоциональной поддержке окружающих в стрессовой ситуации, т. е. девушки придают стрессовой ситуации более сильное эмоциональное значение. Следовательно, они в большей степени, чем юноши, нуждаются в эмоциональной поддержке со стороны значимых людей и психолога.

Таблица 1

Полученные Аанные по МетоАике «СОРЕ»

\begin{tabular}{|c|c|c|c|c|}
\hline Копинг-стратегия & $\begin{array}{c}\text { Аевушки } \\
\bar{X}\end{array}$ & $\begin{array}{c}\text { Юноши } \\
\bar{X}\end{array}$ & $\overline{\bar{X}}^{\text {общее }}$ & $\begin{array}{c}\text { Ранг } \\
\text { (общая } \\
\text { выборка) }\end{array}$ \\
\hline П^анирование & 14,32 & 13,89 & 14,12 & 1 \\
\hline Активное совлаАание & 14,09 & 13,11 & 13,63 & 2 \\
\hline $\begin{array}{l}\text { Позитивное пересрор- } \\
\text { мулирование } \\
\text { и мичностный рост }\end{array}$ & 13,36 & 12,26 & 12,85 & 3,5 \\
\hline Юмор & 14,5 & 10,95 & 12,85 & 3,5 \\
\hline $\begin{array}{l}\text { Полавление } \\
\text { конкурирующей } \\
\text { деятельности }\end{array}$ & 12,18 & 11,74 & 11,98 & 5 \\
\hline Принятие & 11,91 & 11,47 & 11,71 & 6 \\
\hline $\begin{array}{l}\text { Инструментальная } \\
\text { социальная } \\
\text { полАержка }\end{array}$ & 12,05 & 11,11 & 11,61 & 7 \\
\hline САерживание & 10,55 & 10 & 10,29 & 8,5 \\
\hline $\begin{array}{l}\text { Эмоциональная } \\
\text { социальная } \\
\text { подАержка }\end{array}$ & 11,09 & 9,37 & 10,29 & 8,5 \\
\hline
\end{tabular}




\begin{tabular}{|l|c|c|c|c|}
\hline \multicolumn{1}{|c|}{ Копинг-стратегия } & $\begin{array}{c}\text { Аевушки } \\
\bar{X}\end{array}$ & $\begin{array}{c}\text { Юноши } \\
\bar{X}\end{array}$ & $\begin{array}{c}\text { Общее } \\
\bar{X}\end{array}$ & $\begin{array}{c}\text { Ранг } \\
\text { (общая } \\
\text { выборка) }\end{array}$ \\
\hline $\begin{array}{l}\text { Концентрация } \\
\text { на эмоциях }\end{array}$ & 10,95 & 8,63 & 9,88 & 10 \\
\hline $\begin{array}{l}\text { Мысленный ухол } \\
\text { Отрицание }\end{array}$ & 9,77 & 7,79 & 8,85 & 11 \\
\hline $\begin{array}{l}\text { Поведенческий ухол } \\
\text { Использование }\end{array}$ & 7,09 & 6,84 & 6,98 & 12 \\
\hline успокоительных & 6,18 & 5,05 & 5,66 & 14 \\
\hline Обращение к религии & 5,73 & 4,89 & 5,34 & 15 \\
\hline
\end{tabular}

Полученные данные позволили установить, что у девушек и юношей наблюдается различие в субъективном контроле. Одаренные девушки имеют более высокий уровень субъективного контроля над значимыми ситуациями $\left(U_{\text {эмп }}=126,5\right.$ при $\left.p \leq 0,05\right)$, т. е. они более склонны брать на себя ответственность за свои поступки и считают, что события в их жизни в большей степени зависят от них самих.

Более 70 \% всех опрашиваемых одаренных школьников имеют интернальный тип субъективного контроля. Они склонны думать, что важные события в их жизни полностью зависят от них самих, а не от внешних условий, берут ответственность за свои действия и за то, каким образом складывается их жизнь. С помощью критерия Манна - Уитни удалось выявить различия в применении копинг-стратегии отрицания $\left(U_{\text {эмп }}=40,5\right.$ при $\left.p \leq 0,05\right)$ и стратегии поведенческого ухода от проблемы $\left(U_{\text {эмп }}=47\right.$ при $\left.p \leq 0,05\right)$ одаренных с экстернальным и интернальным типами уровня контроля. Одаренные подростки с экстернальным типом уровня субъективного контроля чаще применяют стратегию отрицания стрессовой ситуации и поведенческий уход от проблемы, что выражается в отказе от достижения цели. Стоит отметить, что обе эти стратегии являются непродуктивным совладающим поведением. 
ОБЩАЯ ПСИХОЛОГИЯ, ПСИХОЛОГИЯ ЛИЧнОСТИ

\section{Выводы}

1. Одаренные подростки чаще прибегают к использованию продуктивных копинг-стратегий, чем непродуктивных. Как в стрессовых ситуациях, так и в интеллектуальной деятельности они предпочитают самостоятельно искать способы решения проблемы, проявляя себя достаточно активно, взяв на себя ответственность за свои действия.

2. Пассивный копинг, ориентированный на уход от решения проблемы или отвлечение на другое занятие, является наименее предпочитаемым среди одаренных обучающихся.

3. Преобладающая у большинства одаренных подростков интернальность локуса контроля говорит об их настойчивости в достижении поставленных целей.

4. Одаренные девушки имеют более высокий уровень субъективного контроля, чем одаренные юноши.

5. Между одаренными девушками и юношами выявлены значимые различия в выборе копинг-стратегий: девушки чаще юношей предпочитают эмоциональный копинг и в большей степени ожидают эмоциональной поддержки от окружающих.

Проведенное исследование позволило выделить небольшую группу обучающихся с экстернальным типом локуса контроля, использующих непродуктивные стратегии копинга и испытывающих трудности в социально-психологическом адаптационном процессе. Для данной группы возможна разработка психологической коррекционной программы с целью формирования продуктивных копинг-стратегий. Психологическая поддержка одаренных школьников необходима для дальнейшего развития их потенциала и самореализации в профессиональной сфере.

\section{ЛИТЕРАТУРА}

1. Арон И. С. Личностные особенности одаренного ребенка в структуре психологической готовности к профессиональному самоопределению // Концепт. 2012. № 7. С. 79-83.

2. Belova E., Zinchenko E. Coping behavior of different groups of Russian urban student youth in connection with their frustration // 4th International Multidisciplinary Scientific Conference on Social Sciences \& Arts SGEM 2017. Albena, Bulgaria, 2017. Vol. 17, P. 85-92. DOI: 10.5593/sgemsocial2017/32/ S11.011

3. Давкуш Н. В. Понятие одаренности и особенности ее выявления у детей // Психолого-педагогическое сопровождение одаренных детей: Сборник материалов I научно-практической конференции / Под ред. Н. А. Глузман. Симферополь: Типография «Ариал», 2017. С. 64-69. 
4. Антонова И. Г. Одаренные дети и особенности педагогической работы с ними // Одаренный ребенок. 2011. № 1. С. 46-51.

5. Суднева О. Ю. Одаренные дети: особенности и сложности развития // Современные исследования социальных проблем (электронный научный журнал). 2012. № 11. DOI: 10.24412/FhF3WUQN c4

6. Зинченко E. B. Сопровождение профессионального самоопределения одаренных старшеклассников в условиях непрерывности образования // Мир университетской науки: культура, образование. 2019. № 3. С. 89-95.

7. Dikaia L., PokulE. Brain mechanisms of creative activity of high-creative and gifted people // International Journal of Psychophysiology. 2018. Vol. 131. P. S156. DOI: $10.1016 /$ j.ijpsycho.2018.07.414

8. Габдулхаков В. Ф. Одаренность и ее развитие в условиях взаимодействия общеобразовательной школы и университета. Учебно-метод. пособие. Казань: РИЦ «Школа», 2012. 174 с.

9. Taxonomy of education objectives. The classification of educational goals / Ed. by B. S. Bloom. Handbook 1: Connitive Domain. N. Y.: Longmans, Green and Company, 1956. 207 p.

10. Ziegler A., Stöger H. Expertisierung als Adaptions- und Regulationsprozess: Die Rolle von Bildungs- und Lernkapital // Motivation, Selbstregulation und Leistungsexzellenz / M. Dresel (Hrg.). Münster: Lit, 2011. P. 131-152.

11. Шкуратова И. П., Анненкова Е. А. Личностные ресурсы как фактор совладания с кризисными ситуациями // Психология кризиса и кризисных состояний: Материалы междунар. междисц. симпозиума. Вып. 4. Ростов-на-Дону, 2007. С. 17-23.

12. Eddles-Hirsch K., Vialle W., McCormick J., Rogers K. Insiders or outsiders: The role of social context in the peer relations of gifted students // Roeper Review. 2012. Vol. 34, № 1. P. 53-62. DOI: 10.1080/02783193.2012.627554

13. Sidorenkov A. V., Shipitko O. Y., Obukhova Y. V. The connection between the levels and types of intra group conflict with small groups effectivness // 4th International Multidisciplinary Scientific Conference on Social Sciences \& Arts SGEM 2017. Albena, Bulgaria, 2017. Vol. 17, P. 371-378. DOI: 10.5593/ sgemsocial2017/32/S11.047

14. Зинченко Е. В., Рудя И. А. Стратегии копинг-поведения у молодых женщин, имеющих детей // Северо-Кавказский психологический вестник. 2017. № 15/1. С. 27-34.

15. Хазова С. А. Интеллектуальная одаренность и совладание с трудностями // Вестник Костромского государственного университета им. Н. А. Некрасова. 2008. Т. 14, № 4. С. 162-166.

16. Никольская И. М., Грановская Р. М. Психологическая защита у детей. СПб.: Речь, 2010. 352 с. 
17. Яковлева С. А. Особенности совладающего поведения старшеклассников с учётом локуса контроля // Ученые записки Забайкальского государственного гуманитарно-педагогического университета им. Н. Г. Чернышевского. 2012. № 5. С. 259-263.

\section{REFERENCES}

1. Aron I. S. Personal characteristics of a gifted child in the structure of psychological readiness for professional self-determination. Koncept, 2012, no. 7, pp. 79-83. (in Russ.).

2. Belova E., Zinchenko E. Coping behavior of different groups of Russian urban student youth in connection with their frustration. In: 4th International Multidisciplinary Scientific Conference on Social Sciences \& Arts SGEM 2017. Albena, Bulgaria, 2017, V. 17, pp. 85-92. DOI: 10.5593/sgemsocial2017/32/ S11.011

3. Davkush N. V. The concept of giftedness and features of its detection in children. In: N. A. Gluzman (Ed.). Psychological and pedagogical support of gifted children: Materials of the I Scientific-Practical Conference. Simferopol, Arial Publ., 2017, pp. 64-69. (in Russ.).

4. Antonova I. G. Gifted children and features of pedagogical work with them. Odarennyi rebenok, 2011, no. 1, pp. 46-51. (in Russ.).

5. Sudneva O. U. Gifted children: characteristics and complexity of development. Sovremennye issledovaniya sotsial'nykh problem (elektronnyi nauchnyizhurnal), 2012, no. 11. DOI: $10.24412 / F h F 3 W U Q N$ c4 (in Russ.).

6. Zinchenko E. V. Support of professional self-determination of gifted high school students in the conditions of continuous education. Mir universitetskoi nauki: kul'tura, obrazovanie = The World of Academia: Culture, Education, 2019, no. 3. pp. 89-95. (in Russ.).

7. Dikaia L., Pokul E. Brain mechanisms of creative activity of high-creative and gifted people. International Journal of Psychophysiology, 2018, V. 131, p. S156. DOI: $10.1016 /$ j.ijpsycho.2018.07.414

8. Gabdulkhakov V. F. Giftedness and its development in the context of interaction between secondary schools and universities. Kazan, Shkola Publ., 2012, 174 p. (in Russ.).

9. Bloom B. S. (Ed.). Taxonomy of education objectives. The classification of educational goals. Handbook 1: Connitive Domain. N. Y., Longmans, Green and Company, 1956. 207 p.

10. Ziegler A., Stöger H. Expertisierung als Adaptions- und Regulationsprozess:Die Rolle von Bildungs- und Lernkapital [The role of adaptation and regulation processes in the acquisition of excellence: The role of educational and learning capital]. In: M. Dresel (Ed.). Motivation, Selbstregulation und 
Leistungsexzellenz [Motivation, self-regulation and performance excellence]. Muenster, Lit, 2011, pp. 131-152. (in Germ.).

11. Shkuratova I. P., Annenkova E. A. Personal resources as a factor of coping with crisis situations. In: Psychology of crisis and crisis states: Proceedings of the International Interdisciplinary Symposium. Rostov-on-Don, 2007, Issue 4, pp. 17-23. (in Russ.).

12. Eddles-Hirsch K., Vialle W., McCormick J., Rogers K. Insiders or outsiders: The role of social context in the peer relations of gifted students. Roeper Review, 2012, V. 34, no. 1, pp. 53-62. DOI: 10.1080/02783193.2012.627554

13. Sidorenkov A. V., Shipitko O. Y., Obukhova Y.V. The connection between the levels and types of intra group conflict with small groups effectiveness. In: 4th International Multidisciplinary Scientific Conference on Social Sciences \& Arts SGEM 2017. Albena, Bulgaria, 2017. V. 17, pp. 371-378. DOI: 10.5593/ sgemsocial2017/32/S11.047

14. Zinchenko E. V., Rudya I. A. Strategies of coping behavior among young women with children. Severo-Kavkazskii psikhologicheskii vestnik $=$ NorthCaucasian Psychological Bulletin, 2017, no. 15/1, pp. 27-34. (in Russ.).

15. Khazova S. A. Intellectual giftedness and coping with difficulties. Vestnik of Kostroma State University, 2008, V. 14, no. 4, pp. 162-166. (in Russ.).

16. Nikol'skaya I. M., Granovskaya R. M. Psychological protection in children. St. Petersburg, Rech', 2010. 352 p. (in Russ.).

17. Yakovleva S. A. Coping behavior features of senior pupils taking into account the locus of control. Uchenye Zapiski Zabaikalskogo Gosudarstvennogo Universiteta $=$ Scholarly Notes of Transbaikal State University, 2012, no. 5, pp. 259-263. (in Russ.). 